\title{
Erratum to: The Relationship Between Marijuana and Conventional Cigarette Smoking Behavior from Early Adolescence to Adulthood
}

\author{
Allison N. Kristman-Valente ${ }^{1} \cdot$ Karl G. Hill ${ }^{1} \cdot$ Marina Epstein $^{1} \cdot$ Rick Kosterman $^{1}$ • \\ Jennifer A. Bailey ${ }^{1}$ - Christine M. Steeger ${ }^{1} \cdot$ Tiffany M. Jones $^{1} \cdot$ Robert D. Abbott ${ }^{2}$ • \\ Renee M. Johnson ${ }^{3}$ - Denise Walker ${ }^{4}$ J. David Hawkins ${ }^{1}$
}

Published online: 17 April 2017

(C) Society for Prevention Research 2017

Erratum to: Prev Sci (2017)

DOI 10.1007/s11121-017-0774-4

Due to an oversight, the middle initial of author Tiffany M. Jones was written incorrectly as A rather than $\mathrm{M}$. The original article has been corrected.

The authors regret the oversight.

The online version of the original article can be found at http://dx.doi.org/ 10.1007/s11121-017-0774-4.

Allison N. Kristman-Valente

ankv@uw.edu

Karl G. Hill

khill@uw.edu

Marina Epstein

marinaep@uw.edu

Rick Kosterman

rickk@uw.edu

Jennifer A. Bailey

jabailey@uw.edu

Christine M. Steeger

csteeger@uw.edu

Tiffany M. Jones

tjones03@uw.edu
Robert D. Abbott

abbottr@uw.edu

Renee M. Johnson

rejohnso@jhsph.edu

Denise Walker

ddwalker@uw.edu

J. David Hawkins

jdh@uw.edu

1 Social Development Research Group, School of Social Work, University of Washington, 9725 3rd Ave. NE, Suite, 401, Seattle, WA 98115, USA

2 College of Education, University of Washington, Seattle, WA, USA

3 Bloomberg School of Public Health, Johns Hopkins University, Seattle, WA, USA

4 School of Social Work, University of Washington, Seattle, WA, USA 